up by interview, are summarized. Because of the absence of a death rate this type of injection is recommended as the radical treatment to be tried first.

BIBLIOGRAPHY

(Letters in parentheses refer to Table 2)

ADAMS, W. E., and ROBINSON, R. (194I), Lancet, ii, 555. ANONYMOUS (1923), Brit. $\mathcal{F}$. Surg., 10, 573.

BORSOTTI, I. (1938), Riv. oto-neuro-oftalm., $15,408$.

CAMPBELL, A. M. G. (1948), Lancet, ii, 600 .

CARMICHAEL, E. A., and WOOLLARD, H. H. (1933), Brain, $56,109$.

CAVINA, C. (1932), Riv. ital. Stomatol., 1, 3.

COENEN, H. (I932), Zbl. Chir., 59, 2963

COHEN, I. (1934), Arch. Neurol. Psychiat., Chicago, 31, 21 I.

(a) CUSHING, H. W. (1920a), Amer. F. med. Sci., 160, 157 .

(b) CUSHING, H. W. (1920b), Ұै. Amer. med. Ass., 75, 441.

(c) DANDY, W. E. (1929), Arch. Surg., Chicago, 18, 687.

(d) DANDY, W. E. (1932), Ann. Surg., 96, 787.

DANDY, W. E. (1934), Amer. $\mathscr{f}$. Surg., 24, 447.

(e) FALCONER, M. A. (1949), Ұ. Neurol. Neurosurg. Psychiat., I2, 297.

FERNER, H. (1949), Nervenarzt, 20, 26.

(f) FRAZIER, C. H. (1925), Arch. Neurol. Psychiat., Chicago, 13, 378.

(g) FRAZIER, C. H. (1931), F. Amer. med. Ass., 96, 913.

FRAZIER, C. H., and GARDNER, W. J. (1928), Surg. Gynec. Obstet., 47, 73.

GLASER, M.' A.'(1928), Arch. Neurol. Psychiat., Chicago, 20, 537.

(h) GRANT, F. C. (1938), Ann. Surg., 107, 14.

(i) GRANT, F. C. (1943), Res. Publ. Ass. nerv. ment. Dis., 23, 408.

(j) GRANT, F. C. (1948), Amer. Y. Surg., 75, 42.

GUTNIKOFF, B. (1925), Arch. klin. Chir., 135, 79.

HAERTEL, F. F. (1935), Dtsch. med. Wschr., 6r, 1069.

HARRIS, W. (1920), Proc. R. Soc. Med., 13, Parts I and 2, Clinical Section, 62.

HARRIS, W. (1936), Brit. med. F., i, 457.

HARRIS, W. (1940a), Lancet, ii, $48 \mathrm{r}$.

HARRIS, W. (I940b), Brain, 63, 209.

HEAD, H. (1910), 'Allbutt and Rolleston's System of Medicine,' 2nd edition, London, Macmillan, 7, 540.

(k) HORRAX, G., and POPPEN, J. L. (1935), Surg. Gynec. Obstet.,

HUTCHINSON, J. (1905), "The surgical treatment of facial neuralgia,' London, John Bale and Danielsson.
JAENSCH, C. (1926), Klin. Mbl. Augenheilk., 77, 212.

JEFFERSON, G. (1931), Brit. med. $\mathcal{Y}$., ii, 879 .

KIRSCHNER, M. (1933), Arch. klin. Chir., 176, 581.

KIRSCHNER, M. (1936), Ibid., 186, 325.

(l) KIRSCHNER, M. (1942), Munch. med. Wschr., 89, 235, 263.

KLUGE, A. (1922), Z. ges. Neurol. Psychiat. (Originalien), 76, 372. KOENNECKE, W. (1917), Dtsch. Z. Chir., x40, 225.

KRAYENBUEHL, H. (1936), Brain, 59, 337.

LEWY, F. H., and GRANT F. C. (1938), Arch. Neurol. Psychiat., Chicago, 40, I 126.

MCAULIFFE, G. W., GOODELL, H., and WOLFF, H. G. (1943), Res. Publ. Ass. nerv. ment. Dis., 23, 185.

MORRIS, L. (1931), Lancet, i, 122

NEUGEBAUER, F.' (1918), Zbl. Chir., 45, 565.

(m) ODDSSON, B. (1944), Acta Psychiat., Kbh., 19, 293.

(n) OLIVECRONA, H. (1942), Arsh. Neurol. Psychiat., Chicago,

(o) OLIVECRONA, H. (1947), Acta Psychiat., Kbh., Suppl. 46, 268.

(p) PANNABECKER, C. L. (1944), Arch. Ophthal., N.Y., 32, 456. PENMAN, J. (1949), Lancet, ii, 268.

PENMAN, J., and SMITH, M. C. (1950), F. Neurol. Neurosurg. Psychiat., 13, 36.

PUTNAM, T. J., and HAMPTON, A. O. (1936), Arch. Neurol. Psychiat., Chicago, 35, 92.

(q) RANEY, R., RANEY, A. A., and HUNTER, C. R. (1948),

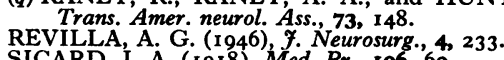

SICARD, J.-A. ( 1918 ), Med. Pr., 106, 60.

SJOEQVIST, O. (1937), Zbl. Neurochir., 2, 274.

SJOEQVIST, O. (r938), Acta Psychiat., Kbh., Suppl. 17.

SJOEQVIST, O. (1939), Acta chir. scand., 82, 201.

TAPTAS, N.'(I93 I), Pr. méd., 39, 239. TROUSSEAU, A. (1861), 'Clinique médicale de l'Hôtel-Dieu de
Paris,' Ist edition, vol. 2, Paris, Baillière. Translated in Publ. New Sydenham Soc., 1868, 35, 105.

WEISENBURG, T. H. (1910), $¥$. Amer. med. Ass., 54, 1600.

ZANDER, P. (1933), Arch. klin. Chir., 178, 242.

(r) ZENKER, R. (1934), Med. Welt, 8, 14

(s) ZENKER, R. (1938), Ergebn. Chir. Orthop., 31, I.

\title{
CERVICAL INTERVERTEBRAL DISC PROTRUSION
}

\author{
By Valentine Logue, M.R.C.P., F.R.C.S. \\ Assistant Neurological Surgeon to St. George's Hospital and the Maida Vale Hospital for Nervous Diseases. Neurological \\ Surgeon to the Royal National Orthopaedic Hospital
}

The prolapsed intervertebral disc in the lumbar region which compresses a nerve root to produce sciatica has become, since its original description in 1934, a commonplace in diagnosis, with its methods of conservative and surgical treatment firmly established, and it seemed only a question of time before the symptomatology of prolapsed discs elsewhere in the spinal column was recognized. In the case of the cervical region however this recognition was somewhat tardy. The first detailed description to be published in an English journal of lateral protrusions causing brachial neuritis appeared only five years ago', and the various syndromes of spinal cord compression from median protrusions and their tendency to mimic degenerative diseases of the cord, although first described in 1928, are even at the present time not widely known.

It is possible for a cervical protrusion, depending on its relationship to the nervous structures, to produce three different syndromes, which are illustrated in Fig. I and which were first described by Stookey:²

I. A lateral protrusion causing pressure on a nerve root to produce brachial neuritis.

2. A more medial protrusion compressing one half of the spinal cord with a Brown-Séquard syndrome.

3. Midline protrusion causing bilateral spinal cord compression.

Occasionally a prolapse may start with symptoms of root compression and then increase in size and produce successively unilateral and then bilateral cord involvement.

\section{Lateral Protrusion with Nerve Root Compression}

Anatomy

There are only six intervertebral discs in the 


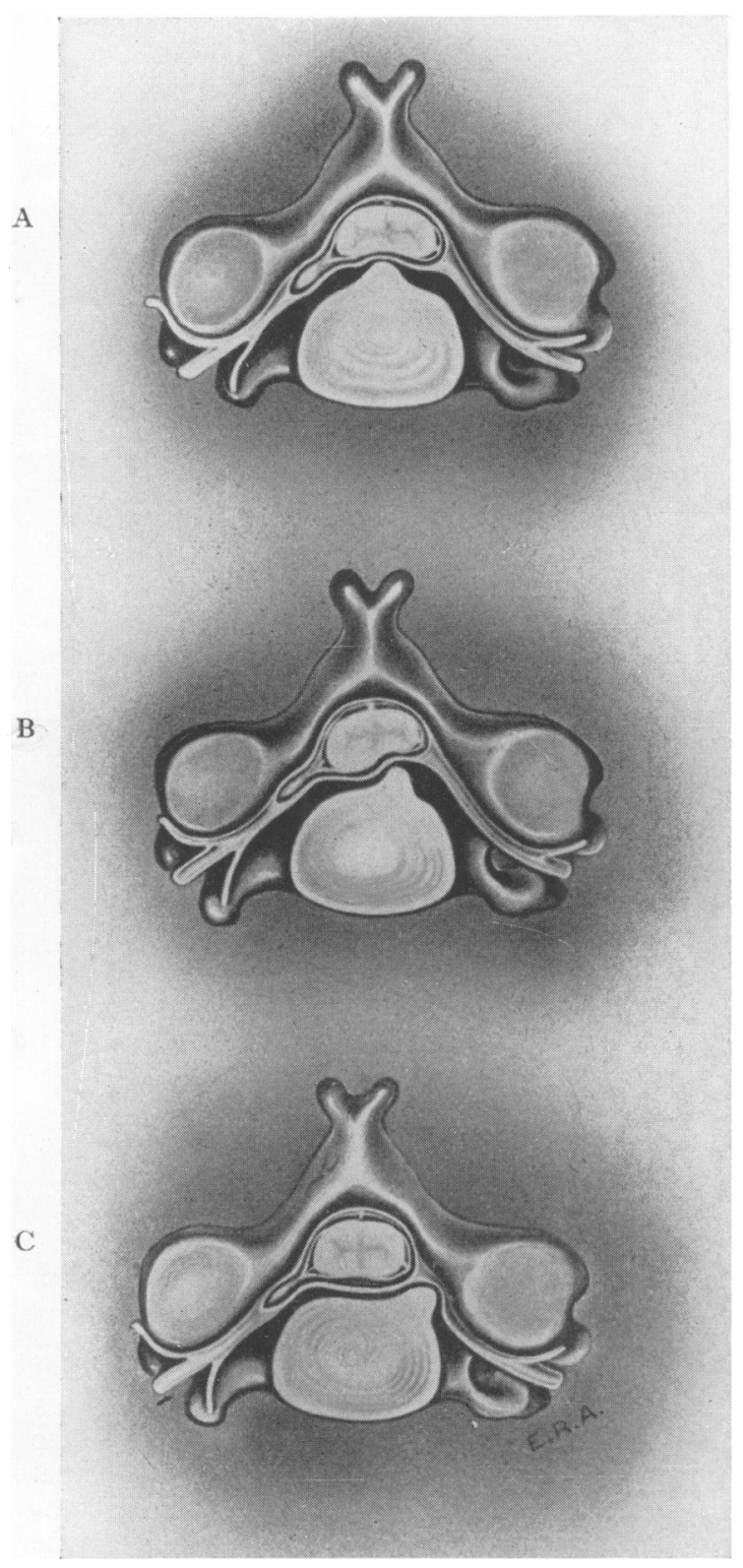

FIG. I

A. Midline protrusion causing pressure on both halves of the spinal cord.

B. Protrusion occurring to one side of the midline, causing pressure only on one half of the spinal cord.

C. Lateral protrusion compressing the nerve root with no involvement of the cord. cervical region(there being none between the occiput and atlas, or between atlas and axis), the first lying between the axis and the third vertebra and the sixth between the seventh cervical and first thoracic vertebrae. (To simplify description the disc level will be referred to by nominating the vertebrae between which it lie, thus the $\mathrm{C}_{5}-6$ and C6-7 discs, which involve the sixth and seventh cervical nerve roots respectively.)

The discs with the greatest mobility and therefore most prone to injury and degeneration are those between vertebrae $\mathrm{C}_{5}-6$ and $\mathrm{C}_{6-7}$, and as would be expected these are the common sites for prolapse. Protrusion may also take place, but infrequently, from the $\mathrm{C}_{4}-5$ and $\mathrm{C}_{7}-\mathrm{D}_{1}$ discs, and very occasionally at the $\mathrm{C}_{3-4}$ and $\mathrm{C}_{2-3}$ levels. The size of an intervertebral disc in the lower cervical region is much less than in the corresponding portion of the lumbar spine (about one-eighth the size) and the protrusion is smaller in bulk, but owing to its closer relationship to the nerve root and the smaller intervertebral foramen, symptoms are as readily produced, although the transverse course taken by the cervical nerves makes it impossible for a lateral prolapse to compress more than one root.

\section{Aetiology}

Trauma plays a much smaller part in cervical than in lumbar disc lesions. Occasionally in younger people there is a history of an automobile accident, a dive into shallow water or a severe blow on the head, but as a general rule no single incident can be blamed. The condition commonly arises from degeneration of the intervertebral cartilage in men between the ages of 30 and 50 , with the actual prolapse occurring from a sudden movement of the head or arm, or on coughing, or even during sleep. Its frequency, compared to lumbar prolapse, is about one to eight.

\section{Symptomatology}

Following a history of repeated attacks of stiff neck or without any previous local symptoms, there is the gradual development of the predominating symptom-pain, which is felt just to one side of the base of the neck, in the supraspinous fossa and over the point of the shoulder, and which in the course of a few days radiates down the arm. Its precise distribution in the arm varies with the individual root affected. In compression of the sixth root $\left(\mathrm{C}_{5}-6 \mathrm{disc}\right)$ the pain is felt in the anterior axillary fold, the antero-lateral aspect of the arm as far as the elbow and along the radial side of the forearm up to, but not as a rule beyond, the wrist. In the case of the seventh root (C6-7 disc) it radiates down the posterior axillary fold, the posterolateral part of the arm and the dorsum of the fore- 


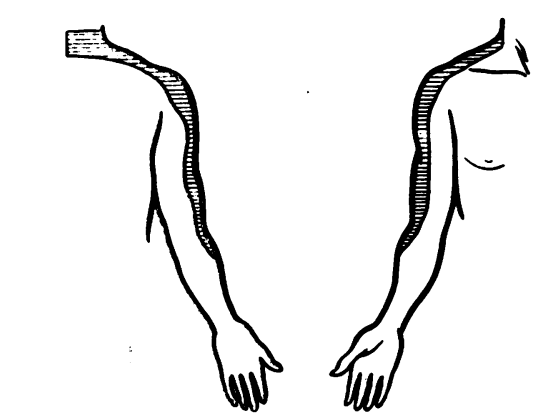

A.
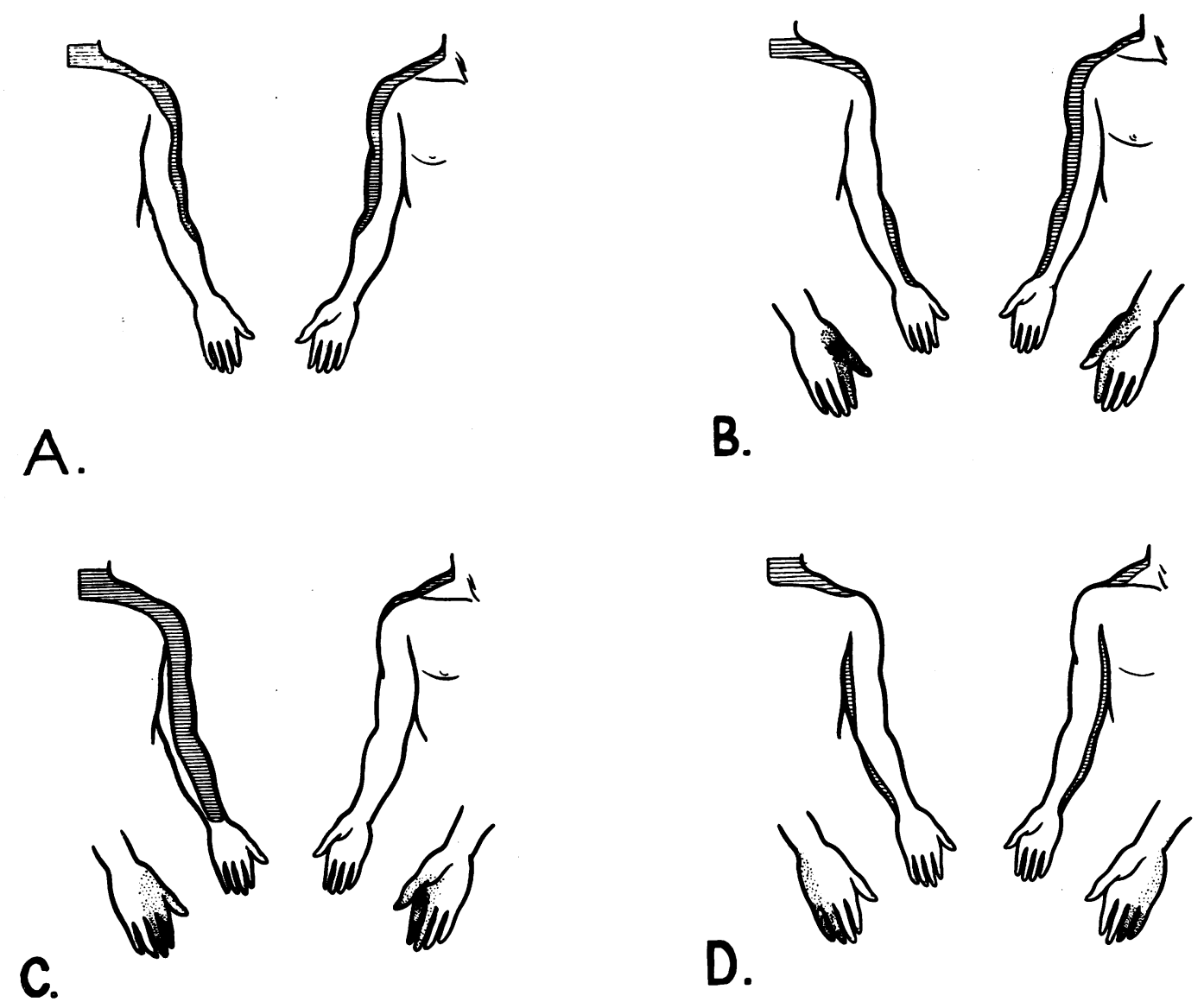

FIG. 2.-To show the distribution of pain (lined areas) and the sensory change (stippling) in cervical nerve root compression. The density of the stippling indicates the frequency with which sensory change occurs.

$\mathrm{A}=5_{\text {th }}, \mathrm{B}=6$ th, $\mathrm{C}=7_{\text {th }}$ and $\mathrm{D}=8$ th root compression.

arm as far as the wrist. The pain may be felt as a continuous band down the arm or localized in areas of maximum intensity, particularly in the deltoid muscle or in the elbow joint or wrist. It has a severe aching character, often preventing sleep and is made worse by use and exercise of the arm, certain movements of the neck, coughing, sneezing, straining and jolting. The patient may find that by elevating and abducting the arm, or flexing the head and inclining it away from the affected side, some relief may be obtained, and learns to adopt this position in a chair or in bed in order to get rest. Occasionally, as well as being felt in the arm, the pain radiates into the pectoralis major and the praecordium, with a sensation of constriction of the chest and difficulty in breathing, and when this occurs on the left side it may simulate coronary thrombosis. In other patients the pain may extend up to the occiput or even into the orhit and behind the eye. The areas in which pain is felt in sixth and seventh root compressions and also in the less commonly affected cervical roots, is shown in Fig. 2.

Paraesthesiae, often extremely unpleasant and variously described as tingling, burning, or as a pins and needles sensation, are felt towards the periphery of the pain distribution, being maximal in the hand and fingers. With sixth root compression paraesthesiae are felt mainly in the base of the thumb, the first interosseous space and radial aspect of the forearm. In the case of the seventh root the areas affected are the back of the hand and the index and middle fingers, with less commonly an extension to the ring finger or the thumb, but occasionally the tips of all the fingers may be involved. This variation in the distribution of the paraesthesiae in individual roots is due to the wide overlap of adjacent nerve segments.

Numbness may develop in parts of the paraesthetic areas and when it involves the fingers it 
often causes difficulty in the manipulation of small objects. There is rarely any complaint from the patient of weakness in the arm and any disinclination to use it is mainly due to pain.

\section{On examination}

It will be found that the neck is held stiffly, sometimes tilted to the opposite side and, despite a full range, the movements are performed slowly and flexion to the affected side may increase the pain down the arm. A reliable test in the acute stage is that of ' neck compression' described by Spurling, ${ }^{3}$ which consists of applying pressure downwards on the head when it is rotated and inclined towards the affected shoulder and which results in a sharp exacerbation of typical pain, the onset of which may be delayed for a few seconds. Conversely, traction on the head with the hands under the chin and occiput will relieve the pain.

Muscle tenderness is often present, particularly in the supraspinatus, pectoralis major, deltoid and extensors of the wrist, either diffusely or in localized ' fibrositic' areas, pressure on which will reproduce the pain and, as in the case of similar nodules in the lumbar region with sciatica, temporary relief may be obtained by local injection with procaine.

The changes in the motor system will vary with the nerve root involved. Thus with sixth root compression the muscles usually affected are the deltoid and biceps which exhibit a flabbiness and loss of tone, and in the more severe cases actual wasting with some degree of weakness. The biceps jerk is reduced or absent. In the case of the seventh root similar changes occur in the triceps and the extensors of the wrist and fingers with diminution of the triceps jerk, the biceps and supinator reflexes being unaffected.

There is often no objective alteration in sensation despite intense paraesthesiae and when it is present is not as a rule very severe. Sensory change is usually maximal over the fingers, but may extend proximally into the hand and forearm. The typical changes are illustrated in Fig. 2. It will be seen that sixth root involvement produces diminution to touch, pain and thermal stimuli over the first interosseous space and the base and dorsal aspect of the thumb, whereas with seventh root compression the terminal phalanx of the index finger is characteristically affected with a lesser change over the rest of the index finger, with often an extension to include the middle finger and the tip of the thumb. In some patients the index, middle and ring fingers are affected. There is usually no change detectable in deep sensation. The more typical features of compression of the sixth and seventh cervical roots may now be summed up:

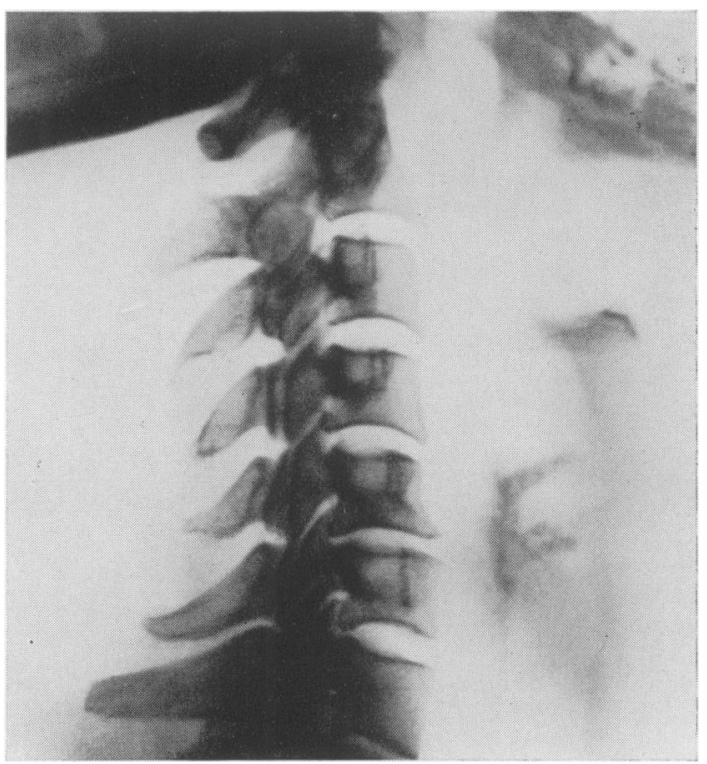

Fig. 3.-A lateral radiograph to show obliteration of the normal cervical lordosis and narrowing of the C5-6 intervertebral disc space with lipping of the adjacent vertebral bodies.

Sixth root. Pain at the base of the neck, supraspinous fossa, anterior axillary fold, antero-lateral aspect of the arm and radial side of the forearm. Wasting of the deltoid and biceps muscles, with reduced biceps jerk. Sensory change over the base and dorsal aspect of the thumb and first interosseous space, sometimes extending to the radial side of the forearm.

Seventh root. Pain in the base of the neck and supraspinous fossa radiating down the posterior axillary fold, postero-lateral surface of the arm and dorsal aspect of the forearm. Wasting and weakness of the triceps and extensors of the wrist, with reduced triceps jerk. Sensory change typically in the index and middle finger, often the tip of the thumb.

It must be emphasized, however, that owing to the variation in pre- or post-fixation of the cervical plexus, the localizing value of these signs is not by any means absolute, and not infrequently for example if may be found that the characteristic features of a seventh root compression are associated with a prolapse demonstrated by myelography or at operation to be at a higher level (C5-6).

Protrusion of discs at other levels in the cervical spine produces pain and paraesthesiae, motor and sensory changes of similar character, which differ merely in their distribution. Prolapse of the C2-3 disc involving the third cervical root has only rarely been reported and one of the best descrip- 


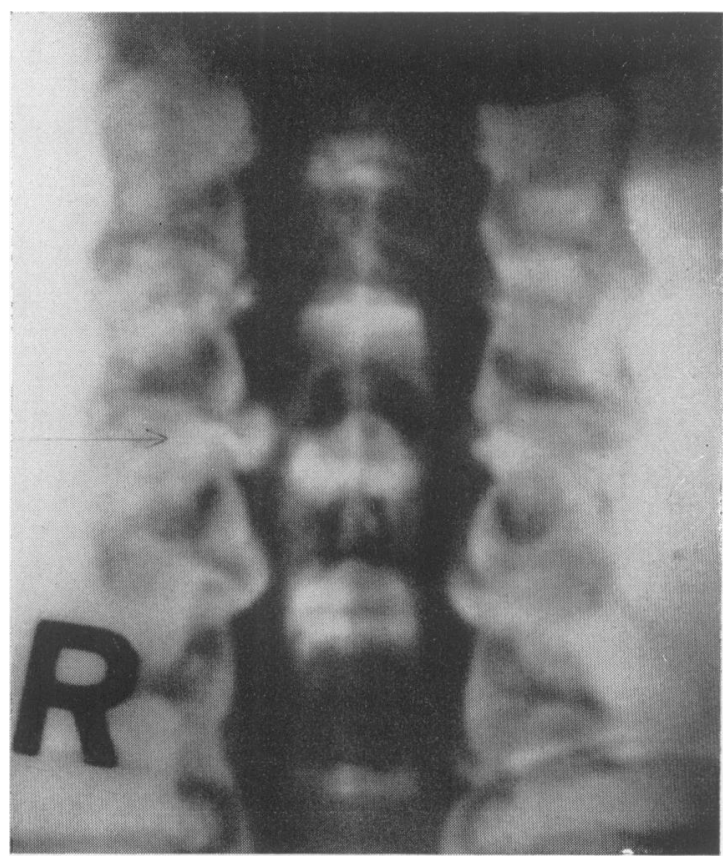

FIG. 4.-The myelogram in a case of lateral protrusion of the $\mathrm{C}_{5}-6$ disc on the right side to show the oval indentation in the column of contrast oil.

tions of such a condition, which was confirmed at autopsy, is that given by Young. ${ }^{4}$ In this case the pain was felt down the right side of the neck. The tongue was elevated on the affected side and difficult to manipulate owing to lack of fixation of the hyoid bone from weakness of the infrahyoid muscles. Pressure on the fourth root by $\mathrm{C}_{3-4}$ prolapse produces pain in the side of the neck extending to the clavicle, tip of the shoulder and supraspinous fossa. $\mathrm{C}_{4}-5$ prolapse will cause pain in the neck and top of the shoulder, extending down the outer side of the deltoid and arm to the elbow, often with weakness and wasting of the supraspinatus and deltoid, and sensory change over the outer aspect of the arm. $\mathrm{C}_{7}-\mathrm{D}_{1}$ protrusion with compression of $\mathrm{C} 8$ root produces pain in the neck and supraspinous fossa radiating down the inner aspect of the axilla and inner side of the forearm and hand, with hypalgesia particularly of the ring finger, and some weakness of the intrinsic muscles of the hand, a clinical picture often erroneously attributed in the past to a 'scalenus anticus syndrome.'

\section{Investigations}

Radiography. Plain X-rays of the neck may demonstrate no abnormality, but the usual change is some flattening of the cervical lordosis without scoliosis, and a narrowing of the relevant disc space with lipping of the adjacent vertebrae (Fig. 3). These changes, however, are not infrequently seen in middle-aged people without symptoms of root compression and therefore cannot be relied upon as being conclusive of prolapse, but are suggestive when taken in conjunction with the clinical features.

Myelography. The diagnosis of brachial neuritis due to a cervical disc lesion is essentially a clinical one and there is as a rule no need for confirmation by myelography unless there is the question of a spinal neoplasm. When, however, surgical removal is contemplated myelcgraphy is an important preliminary, not only to confirm the diagnosis but accurately to localize the level, and for this it is a more reliable investigation than in the case of lumbar protrusions. The typical appearances seen in a lateral prolapse consist of ( $\mathrm{I})$ in small disc lesions merely a lack of filling of the root sheath and (2) in the larger protrusions an oval or triangular indentation in the side of the column of contrast medium, as well as obliteration of the root sheath (Fig. 4).

\section{Treatment}

There is in this condition, to a greater degree than is the case in sciatica, a spontaneous tendency towards recovery, so that the early treatment is always conservative and its chances of success are great, most cases being pain free in six to eight weeks. Rest in bed is the basis of treatment, the patient usually being more comfortable propped up with the arm supported. In the more severe cases traction on the head with a neck sling, using a weight of 8 to ro lb., often has a dramatic effect in relieving pain. It need not be constantly applied, but can be put on during the day and discontinued at night, and the extent to which it is used will depend on the relief it produces and the powers of tolerance of the patient. If traction is to have any effect it will be noticeable within the first two to three days and it is then continued for three to four weeks. After this the patient is allowed up and wears a moulded plastic or leather collar which should be continued for three months and then gradually discarded. In less severe cases and particularly in patients who, for one reason or another, wish to remain ambulant, it is often possible to relieve the pain by keeping the arm abducted and elevated, either on an aeroplane splint or more satisfactorily on an abduction plaster, which probably act by relieving tension on the nerve roots. This is retained for four to six weeks and should be followed by the wearing of a collar.

Manipulation of the neck is sometimes employed and may help some patients, but it often makes the symptoms worse and it carries the 
potential danger of producing a further protrusion of the disc against the spinal cord, with disastrous results.

\section{Operative Treatment}

The indications for surgery in nerve root compression are as follows:

(a) Development of signs of spinal cord involvement.

(b) Severe pain persisting despite an adequate trial of conservative methods.

(c) Persistent symptoms, which although not severe, prevent the patient from working over a long period.

(d) Recurring attacks of pain at frequent intervals.

(e) Severe sensory change in the fingers.

The indications under Groups (a), (b) and (c) require no comment. In Group (d) no definite rule can be laid down, for it will depend mainly on the patient's tolerance, but I have found that most cases who have had three attacks within 18 months to two years want something more permanent in the way of relief. In Group (e) although the pain may no longer be an important feature, operative removal may occasionally be required for certain people, such as musicians, who require perfect sensation in their fingers. I recently had a case of a cartographer who was left with a numb index finger and thumb tip from a $\mathrm{C}_{7}$ root compression and as a result was unable to manipulate the fine pen used in map making. After removal of the protrusion sensation improved and he was able to resume his occupation.

\section{Operative Technique}

The sitting position is probably the best for this operation, but due recognition must be given to its occasional dangers.

As there is no local anatomical landmark in the lower cervical region to guide one, such as the first piece of the sacrum in lumbar operations, it is best to make a fairly long midline incision from the axis to the spine of $\mathrm{C}_{7}$ and then to count the vertebrae down from the large and umistakable spinous process of the axis. A unilateral separation of the muscles from the bone is then made, the relevant interspace exposed, and the adjacent margins of the laminae above and below nibbled away. This opening can be extended laterally by removing the margin of the facet with a dental chisel. The ligamentum flavum is cut away to reveal the nerve root kinked backwards by the protrusion, which is rarely more than $5 \mathrm{~mm}$. in diameter and more often the size of a match head. As soon as the annulus is incised separated portions of cartilage may extrude in a manner similar to protrusions in the lumbar region and removal is simple, but sometimes the prolapse is of bony hardness and will have to be chiselled away. .It is not necessary to curette the remainder of the disc.

The results following surgical removal are as good as in the case of lumbar discs, the pain usually disappearing immediately after operation, but paraesthesiae may persist for one or two weeks if the root has been too firmly retracted. The chances of recurrence are slightly less than for lumbar protrusions.

\section{Spinal Cord Compression}

The recognition of cervical prolapsed discs first came about because of the syndromes of spinal cord involvement which they produced, and the earlier literature is concerned entirely with their effect on the cord (although the protrusions were cartilage), and it is only in recent years that their thought at first to be chondromata arising from the importance as a cause of root compression has become known. The proportion of cord to root compressions is about one to five. As described earlier (Fig. I), if the protrusion arises to one side of the midline it will tend to compress one half of the spinal cord, producing a partial BrownSéquard syndrome, and if it arises in the midline it will produce bilateral cord compression.

\section{Unilateral Cord Compression}

The evidence of unilateral compression of the spinal cord is shown in its most typical form by signs (I) in the arm of root compression, particularly of atrophy and fibrillation in the muscles innervated by it, and with or without root pain, (2) of pyramidal tract involvement in the lower limb on the same side as the affected arm, and (3) of spinothalamic tract disturbance in the trunk and leg on the opposite side. Tactile sensation may be slightly impaired but joint, muscle, position and vibration sense are characteristically spared. There is no alteration of sphincter control. In sharp distinction from the laterally placed discs causing brachial neuritis, there are often no symptoms or signs referable to the neck.

This particular type of partial Brown-Séquard phenomenon showing such precise and selective involvement of the spinal cord is highly characteristic of unilateral disc compression, the only other lesion likely to produce a comparable picture being a small meningioma growing in a similar situation to the protrusion.

Owing, however, to the dissociated character of the sensory loss it may appear to those unfamiliar with this syndrome, that the condition is one of an intramedullary lesion of the cord, such as a glioma or degenerative disease, and much valuable time may be lost before the correct conclusion is arrived 
at, during which irreparable damage occurs to the cord.

The diagnostic difficulties are further increased by the fact that the manometrics of the spinal fluid frequently show no evidence of block and the protein content of the c.s.f. shows little or no increase.

Variations of this typical clinical picture commonly occur and add to the diagnostic problem. In some cases there may be spasticity with increased reflexes in the affected upper limb, with no evidence of atrophy or fasciculation, and this spasticity may involve muscles innervated from cord segments higher than that of the compressed level, a phenomenon which is still unexplained. In other cases there may be no symptoms or signs in the upper limb referable to the nerve root at the level of the compression and the patient presents solely with spasticity in one leg and spinothalamic changes in the opposite half of the trunk and leg.

The changes in sensation may also vary. The upper level of pain and temperature loss is always several segments (never less than four) below the level of compression, as might be expected from the knowledge of the oblique course taken by the crossing spinothalamic fibres, but what is more important is that it may be a considerable distance below the compression, on the lower abdomen or thigh, and even then it tends to have a sharply demarcated upper border rather than a fading edge of hypalgesia. It can be seen that in a patient exhibiting a well-defined level of pain and temperature loss low on the trunk on one side, with pyramidal involvement in the opposite leg and with no symptoms referable to the neck or arms, that attention will tend to be focused on the thoracic portion of the spinal cord, and it is only a familiarity with these varied syndromes of cervical disc protrusion which will suggest a careful myelographic screening of the cervical portion of the spine if the thoracic region is found to be normal.

Some of these features are shown by the following case:

Case I. A lady of 38 years. Six months before admission she noticed a heaviness and stiffness in the right arm with impairment of fine movement in the fingers. One month later stiffness appeared in the right leg and she caught her toes when walking. Three weeks after this she developed a burning sensation in the left side of her chest with a feeling of pins and needles in the left calf, and she noticed she could not feel the difference between hot and cold water with the left leg. There was no sphincter disturbance. These symptoms had tended steadily to get worse, but for a fortnight before admission there had been a little improvement.

On examination there was a full range of neck movement without pain or local tenderness.
There was no wasting or fasciculation in the upper limbs. The right arm showed generalized weakness with considerable spasticity, exaggerated reflexes and a Hoffman's sign. The right leg was even more spastic with ankle and patellar clonus, exaggerated reflexes and a brisk extensor plantar response. The abdominal reflexes were absent on the right. On the left side of the trunk at the fifth thoracic dermatome there was a sharply defined level of hyperalgesia below which there was analgesia to pain and thermal stimuli. This sensory change extended down to cover the whole of the left leg. Tactile sensibility was affected to a much slighter and more variable degree over this area. There was no involvement whatsoever of joint, position or vibration sense in any limb.

$X$-rays showed narrowing of the $\mathrm{C}_{5}-6$ disc space with osteophytic lipping.

Myelography revealed a partial block extending from the lower border of the sixth to the lower border of the third cervical vertebrae, the contrast medium tending to flow slowly along either side of the dural sac. The appearances were suggestive of an intramedullary tumour.

At operation a prolapse from the $\mathrm{C}_{5}-6$ disc measuring $I \mathrm{~cm}$. across was found lying to the right of the midline and the loose cartilage was removed. There was a small area of degeneration about $2 \mathrm{~mm}$. in diameter in the overlying cord.

This case illustrates many of the features; spasticity in the arm without pain, muscle wasting or fibrillation, and spasticity in the leg, with pain and temperature loss on the opposite side of the body, having a sharp upper margin seven segments lower than the level of compression, and with no involvement of vibration, joint and position sense, or of the sphincters.

It is a strange fact that a small protrusion into the spinal canal, usually less than I $\mathrm{cm}$. across, which is not ' compressing' the cord in the usual sense of the term but merely indenting it, should produce such localized and severe damage, which is evident on clinical examination by the severity of the long tract disturbances, and at operation by the degeneration to be seen in the substance of the cord. This may appear as a soft, white atrophic area or a grey translucency, indicative of actual destruction and absorption of the nerve fibres, which is a degree of degeneration that is rarely seen even with the gross distortion produced by the larger meningiomas or neurofibromas. These changes would appear to be due to two factors, one is the physical hardness of the prolapse, much harder than any of the common tumours presenting in the spinal canal and the second, the fact that the spinal cord is securely tethered by the dural sheaths of the nerve roots 
and the ligamenta denticulata, so that it cannot move backwards away from the protrusion and any movement of the neck, particularly flexion, pulls the cord firmly across the surface of the disc and this repeated friction produces the damage.

\section{Bilateral Cord Compression}

Bilateral cord compression from a midline disc typically manifests itself by signs in the trunk and legs of involvement (I) of both pyramidal tracts and (2) of both spinothalamic tracts, with (3) tactile sensibility affected either slightly or not at all, and joint, position and vibration sense and sphincter control being completely spared. Characteristically there are no symptoms referable to the neck. The changes which occur in the upper limbs are variable, in some cases there is subjective numbness down the inner borders of the forearm and hand, usually not referable to the nerve root at the level of the compression, and often associated with hypalgesia in this area with a little wasting and weakness of the intrinsic muscles of the hand. In other cases there may be spasticity of the arms with exaggerated reflexes and a Hoffman's sign, and not infrequently there may be no changes in the upper limbs at all.

There is a tendency for the symptoms and signs to vary in severity, particularly if the patient is confined to bed, when it may be found that the legs become less spastic and the level of sensory change may fall many segments.

These are the typical manifestations of the condition but a more important syndrome from the diagnostic point of view, which has been emphasized by Bucy, ${ }^{5}$ consists solely of bilateral motor involvement in the legs with a disturbance of gait and balance and with no sensory changes whatsoever. The spasticity tends to be out of all proportion to the weakness, and the patient may notice that a spontaneous clonus appears in the legs when sitting down or driving a car. The interference with balance causes the patient to walk on a wide base and to turn slowly, without however any ataxia in the heel/knee/shin test being demonstrable. All modalities of sensation are unaffected and there is no interference with sphincter control. It can be appreciated that such a syndrome with its main effect on the motor system can easily be mis-diagnosed as disseminated sclerosis, or if root pressure signs of wasting of the intrinsic hand muscles also occur, as amyotrophic lateral sclerosis.

The diagnosis is rendered even more difficult by the fact that the term ' compression' of the spinal cord has come to be associated exclusively with the changes seen in the presence of a large spinal tumour, particularly a block on Queckenstedt's

\begin{tabular}{c|l|l|l}
\hline $\begin{array}{c}\text { Case } \\
\text { No. }\end{array}$ & $\begin{array}{c}\text { Type of } \\
\text { Compression }\end{array}$ & Manometry & $\begin{array}{c}\text { Protein } \\
\text { Content } \\
\text { of C.S.F. }\end{array}$ \\
\cline { 2 - 3 } I & Unilateral & $\begin{array}{l}\text { Partial block } \\
\text { No block }\end{array}$ & $\begin{array}{l}\text { Per cent. } \\
80 \mathrm{mgm} .\end{array}$ \\
2 & Bilateral & No $\mathrm{mgm}$. \\
3 & Unilateral & No block & $45 \mathrm{mgm}$. \\
4 & Unilateral & No block & $45 \mathrm{mgm}$. \\
5 & Bilateral & Partial block & $40 \mathrm{mgm}$. \\
6 & Bilateral & No block & $35 \mathrm{mgm}$. \\
7 & Unilateral & No block & $25 \mathrm{mgm}$. \\
8 & Bilateral & No block & $20 \mathrm{mgm}$. \\
9 & Bilateral & No block & $20 \mathrm{mgm}$. \\
ro & Bilateral & No block & $20 \mathrm{mgm}$. \\
\hline
\end{tabular}

FIG. 5.-A summary of the findings in ten cases of cervical disc protrusion producing uni- or bilateral cord compression.

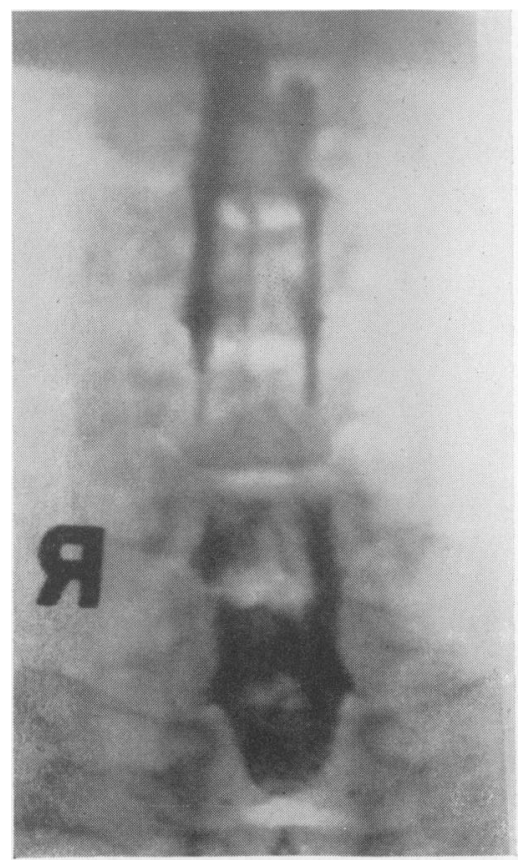

FIG. 6.-The myelogram in Case (2), showing the partial block extending from the upper border of the fourth to the lower border of the sixth cervical vertebra with a thin incomplete column of opaque medium all round the sides of the obstruction.

test, xanthochromia and a high protein in the c.s.f., and the belief still lingers that in cases where no block can be demonstrated by manometry a myelogram will not be informative. The converse, however, is true in cervical disc protrusions causing bilateral (and unilateral) cord compressions; there is usually no block or at most a 


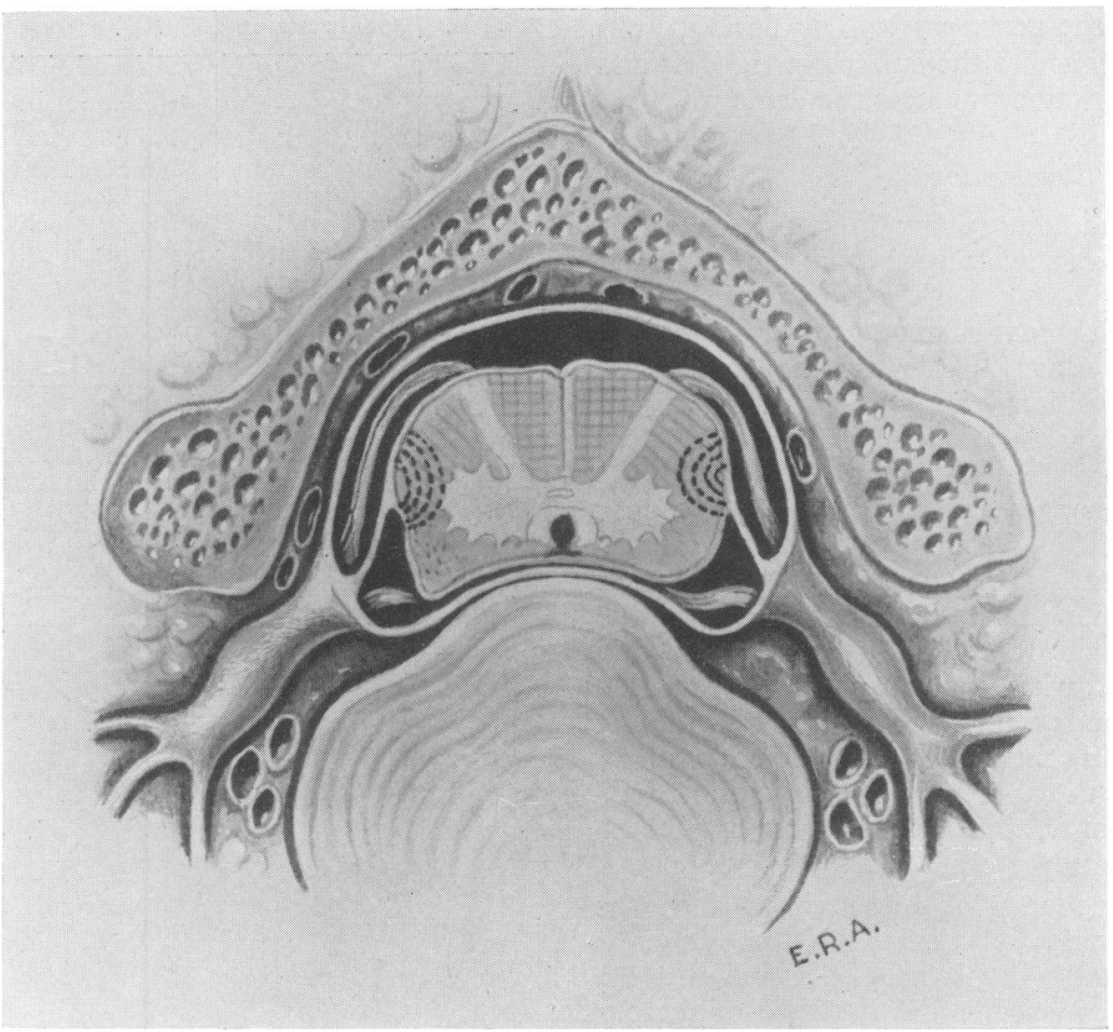

Fig. 7 (after Kahn).-To show the lines of stress (dotted lines) at and behind the attachment of the dentate ligaments.

partial block on manometry, there is no xanthochromia in the fluid and the increase in protein is small or absent. Fig. 5 illustrates the findings in ten cases of median disc protrusions, causing unilateral or bilateral cord compression. It will be seen that no less than eight cases showed no block and the protein content was normal in six cases (taking $40 \mathrm{mgm}$. per cent. as the upper limit of normal).

The following case illustrates many of the diagnostic features:

Case 2. A man aged 37. Four months prior to admission he slipped and fell heavily on to his buttocks, but did not directly injure his head or neck. Two weeks later he developed numbness in the fourth and fifth fingers of both hands. Twelve weeks before admission he noticed stiffness of both legs and an unsteadiness in walking and disturbance of balance particularly on turning quickly, and there was also a sensation of woolliness under the soles of both feet. There were no symptoms referable to his neck. He was admitted at that time to a neurological department where a lumbar puncture was performed, which showed no evidence of block, and a protein of $50 \mathrm{mgm}$. per cent. in the c.s.f. A diagnosis of disseminated sclerosis was made and he was discharged. Two weeks later he began to feel a tightness across the front of his thighs and also developed some urgency of micturition.

Examination on Admission. Movements of the neck were unrestricted and painless. There was a little wasting of the interossei of the left hand and the fingers assumed the main-en-griffe position. The reflexes in both arms were exaggerated. There was a mild diminution to all forms of cutaneous sensation along the inner borders of the forearms, hands and fourth and fifth fingers on both sides. The lower abdominal reflexes were absent. In the lower limbs there was a slight generalized weakness, more marked on the left, with considerable spasticity, ankle clonus, exaggerated reflexes and bilateral extensor responses. He walked unsteadily on a wide base. Sensation 


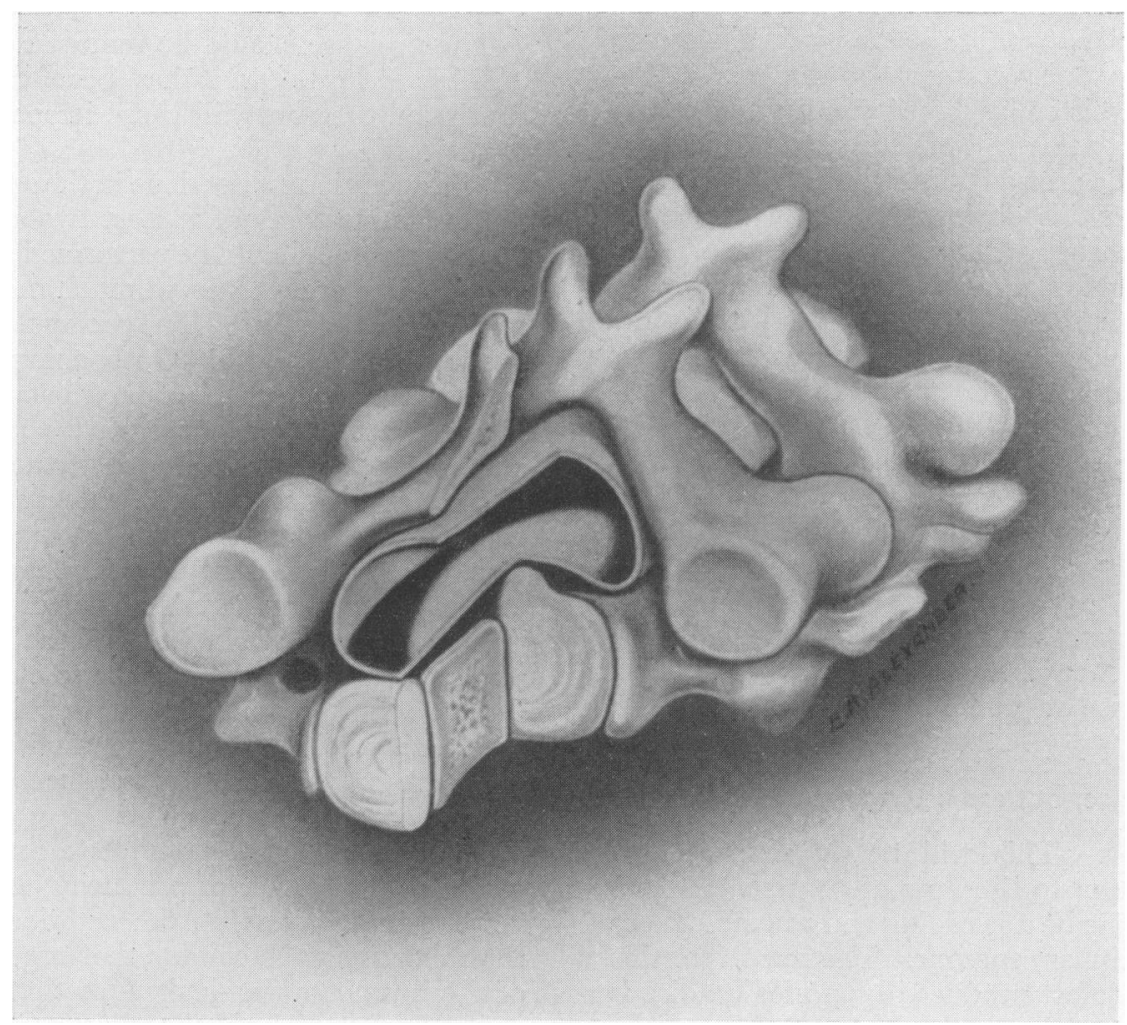

FIG. 8.-A diagram illustrating the myelographic appearance of a central disc protrusion. The spinal cord is not shown, and the left half of the superior disc and vertebra have been removed. The elevation of the dura for some distance above and below the prolapse can be seen producing the elongated filling defect with the contrast medium (shown in black) passing round the sides.

to light touch, pin-prick and thermal stimuli, and joint and position sense were normal. There was a little impairment of vibration sense at the knees and ankles.

$X$-ray of the cervical spine showed no abnormality.

On spinal puncture there was no evidence of block and the protein of the c.s.f. was $50 \mathrm{mgm}$. per cent.

Myelography performed via the cisternal route showed the contrast medium to be held up at the upper border of the fourth cervical vertebra and then trickle past very slowly on either side. When run up from below there was a partial block at the lower border of the sixth vertebra and again it ran slowly along the sides. The appearances were suggestive of an intramedullary tumour (Fig. 6).

At operation a large central protrusion was found at the $\mathrm{C}_{5}-6$ disc level and two loose pieces of cartilage were removed.

Post-operatively paraesthesiae in the arms took three weeks to disappear. The power returned in the intrinsic muscles of the left hand and the spasticity was less marked in the legs, but now, nearly two years after operation, he has still a little unsteadiness on walking and turning quickly.

It is an interesting fact that the predominant symptom in these anterior compressions of the cord by prolapsed discs, both uni- and bilateral, is referable to the pyramidal tracts and is often much more marked than the spino-thalamic tract disturbance despite the closer anatomical relationship of the latter to the protrusion. If the cord were being generally ' compressed' by a large lesion, this could perhaps be explained by the greater vulnerability of the large diameter nerve fibres of which the pyramidal tract is mainly composed, but as pointed out earlier, disc lesions do not cause a general compression of the cord, but merely an indentation. The probable explanation of this phenomenon is that given by $\mathrm{Kahn}:^{\circ}$ As the dural sac is firmly tethered in the spinal canal by the 
dural sheaths covering the nerve roots, and the spinal cord is fixed within the sac by the ligamenta denticulata, any displacement of the cord backwards will be resisted by these latter ligaments, and as seen in Fig. 7 this will produce a localized zone of tension in the area adjacent to their attachment, and as it is in this situation that the pyramidal tracts are lying they will be particularly subject to this disrupting force. This force will vary with movements of the neck and will tend to be increased by flexion. Owing also to this fixation by the dural sheaths and ligaments the cord is prevented from being displaced backwards against the unyielding vertebral laminae so that the fibres in the posterior columns are spared.

\section{Investigations}

Spinal puncture, as already mentioned, usually shows no evidence of block, at most a partial block with a slight rise of protein.

$X$-rays of the cervical spine may show narrowing of the disc space, but are often normal.

Myelography. This will nearly always show some obstruction to the flow of contrast, but the appearances may be misleading and resemble those of an intramedullary tumour. The reason for this is that filling defect produced by a median disc is often several times larger than the actual size of the prolapsed portion of cartilage owing to the fact that as it projects backwards into the spinal canal, it lifts up the dura and separates it in a tent-like fashion from the bodies of the vertebrae for some distance above and below the disc level. This elevation of the dura will be greatest over the top of the disc and least at the sides of the spinal canal. As the patient is normally screened in the prone position with the neck extended, the contrast material flows along the ventral aspect of the dural sac and will be held up by the indentation in the dura some distance away from the actual disc level and will tend to flow round the sides. This picture of an elongated filling defect with a trickle of contrast on either side is usually taken as indicative of an intramedullary lesion Fig. 8.

\section{Operative Treatment}

The prolapse should be removed with the least possible delay after it has been diagnosed, for continued pressure will cause irreparable damage to the cord.

The operation is best done in the sitting position. A full laminectomy of at least two and preferably three vertebrae should be performed as wide access is needed in order to avoid much manipulation or retraction of the cord. The prolapse is exposed by a transdural approach. On opening the dura the cord will be seen to be kinked backwards by the prolapse and often degenerative changes may be seen in its substance. Three of the dentate ligaments are divided on each side and the cord is gently rotated to expose the glistening bulge of the disc, which is not as a rule more than a centimetre in diameter. The anterior layer of the dura and then the annulus are incised and the loose cartilage removed. No attempt is made to curette the disc. Extreme gentleness in moving the spinal cord is the dominating feature of the operation, particularly if there are any degenerative changes visible in it. In cases with severe cord degeneration it is probably safer not to attempt to remove the disc owing to the chance of producing an acute transverse lesion (probably from anterior spinal artery thrombosis) and to confine the surgery to division of the ligamenta denticulata, so that the cord can move backwards off the disc. Sometimes the protrusion consists of a general bulge of the disc in the spinal canal, with lipping of the vertebrae above and below, and without prolapse of the nucleus pulposus. It extends from one side of the spinal canal to the other as a median bar, the cord being kinked backwards by it, and the symptoms which result appear to be caused by repeated rubbing of the cord across the disc whenever the neck is flexed. Clinically the condition is associated with a long history, is not uncommon in women and the symptoms, which usually appear in the arms as well as the legs, are bilateral from the start. This type of protrusion is difficult to deal with as it is impossible to remove the bony hard bulge without danger to the cord and the only treatment is division of the dentate ligaments.

\section{REFERENCES}

I. ELLIO'TT, F. A., and KREMER, M. (1945), Lancet, i, 4.

2. STOOKEY, B. (1928), Arch. Neurol. and Psych., 20, 275.

3. SPURLING, R. G., and SCOVILLE, W. B. (1944), Surgery, Gynaecology and Obstetrics, 78, 350.

4. YOUNG, J. H. (1948), Med. Fournal Australia, 2, 234.

5. BUCY, P. C., HEIMBURGER, R. F., and OBERHILL, H. R. (1948), fournal Neurosurgery, 5, 471.

6. KAHN, E. A. (1947), Fournal Neurosurgery, 4, $19 x$. 